\title{
Time for Decarbonization of Conservation and Development Projects? The Political Ecology of Carbon Projects
}

Published: 3 December 2015

Keywords: Africa; biodiversity conservation; carbon sequestration, REDD+

Carbon Conflicts and Forest Landscapes in Africa Leach M, Scoones I (Eds.)

Routledge: London, UK. 2015

230 p.; ISBN: 978-1138824836

The globe's first carbon projects were designed and implemented approximately 20 years ago following scientific insights that emissions of greenhouse gases needed to be mitigated. Visible in some of these early projects were the important aspects of social governance and local benefit sharing. The projects promised to be a panacea to environmental, social and economic problems in remote rural areas of developing countries. However, it took another decade before a wave of hundreds of carbon projects were launched. Many of the projects were offered under the mechanism of REDD+ (Reducing Emissions from Deforestation and forest Degradation, plus the role of conservation, sustainable forest management and carbon enhancement), as well as under a variety of voluntary schemes and national programs, public-private partnerships, and forestry-based investment initiatives. As decision-makers prepare the Conference of the Parties of the United Nations Framework Convention on Climatic Change in Paris (COP21), Earthscan has released a book entitled 'Carbon conflicts and forest landscapes in Africa', edited by Melissa Leach and lan Scoones. According to the editors, the focus of the book is on what happens on the ground when carbon forestry projects arrive, what types of projects work, and, equally important, what doesn't work.

Leach and Scoones launch the collection of ten chapters with a discussion of "political ecologies of carbon in Africa". This is followed by a review of different carbon projects and policies. Finally, a variety of case studies are presented, concentrating on Ghana, Kenya, Sierra Leone, Tanzania, Uganda, Zambia, and Zimbabwe, clearly achieving a broad representation of different African socioecological and political contexts. Adding to the geographical diversity, the contributing authors also represent a variety of academic perspectives, including anthropologists, geographers, economists, natural resource managers, agronomists, and social scientists. This broad spectrum makes clear that the reader should not expect strict assessments of carbon project impacts on forest ecosystems or biodiversity in general. Lacking in the book, however, are contributions and perspectives from 'climate protectionists', conservationists, carbon brokers, or donors of carbon projects, which would have made the book more comprehensive and balanced.

This piece of work is a critical revision of carbon projects as economic interventions that provide new value to ecosystems suffering from unsustainable use. Due to their economic relevance they have even become an interesting object for brokers, traders, and consultants and often developed a certain potential to create social distortions on the ground. The editors present and discuss "a new round of 'missionary' development activity" advocated by donors and NGOs. Indeed, carbon projects are just another form of socioeconomic and legal mechanismspaid for significantly by foreign donations-that can alter or restrict access to local natural resources and potentially change local livelihoods. They represent interventions in extremely complex socio-ecological and political landscapes of forestry/ecosystem management, where unsatisfied needs of local people combine with governance and enforcement deficits. The projects are stacked on top of many layers of conventional development projects and cannot escape their socio-cultural and historical contexts, or the standard problems related to the mobilization and engagement of local actors. In this context, also due to 
their design that differs from conventional projects, "carbon projects face a greater challenge in explaining themselves" (Mickels-Kokwe and Kokwe, p. 140).

The two introductory chapters alone are a valuable compilation of facts about carbon projects, their technicalities, and their political ecology. The chapters' relevance goes far beyond the African context. Furthermore, they are meaningful in a broader context of a neoliberal and commodified model of ecosystem management, which is currently expanding and diversifying. The case studies compile a compelling amount of evidence of failures and conflicts. They also give voice to local stakeholders reflecting their perceptions of carbon projects, regarding both design and implementation. As the editors point out, the authors do not go as far as simply rejecting carbon projects. The reader who examines this book closely can come to conclusions that are grim and depressing: Carbon projects often stand for big promises and poor delivery, for high expectations that fail to match rigorous requirements, for gaining carbon finance, for 'fortress conservation' that forcefully excludes local people, sidelining farmers' knowledge, for the displacement of food production as well as for benefits limited to old or new elites, just to summarize a few findings presented in the book. Indeed, it is disheartening to find so much evidence of missed opportunities and failure after so many years of implementing carbon projects. These seem to have significantly contributed to the credibility crisis of biodiversity conservation and ecosystem management; the concept of 'big carbon money' may have both corrupted and oversimplified the narrative of an ethically needed conservation.

Science seems to show that "smallholders are not a significant cause but rather a significant victim of climate change. Therefore, social justice calls for compensation, rather than making them bear the costs of mitigation programmes" (Atela, p. 92). At the end of the day, carbon projects contribute to the commodification of the irreplace- able fundaments of our life, fueling an ongoing privatization of ecosystem management and governance. They further upscale "authority and agenda setting in policy [that] has occurred due to donors and transnational bodies" such as certification organizations, UN, World Bank etc. (Nel, p. 96).

The need for the conservation of functional and intact forests is undeniable and non-negotiable. But if carbon projects failed to enable and empower local actors and adequately compensate them for unavoidable opportunity costs, all this that once started as an apparently good idea has not just led to disappointment, but has become part of the problem. It is recommendable to carefully study this trend towards a flow-based governance of commodified carbon and biomass. Much more is to come under the rising paradigm of bioeconomy and a complexifying 'green grabbing scenario'. In this context, this book is a very valuable source. It gives important recommendations for the incremental improvement of carbon projects including pleas for taking social justice and equity seriously. Equally important, it provides tangible arguments for pressing the 'reset button' in forest carbon governance. Game over? Is it time for decarbonization of conservation and development projects? This book should also inspire further critical inquiry that helps us to competently question 'greened' neoliberal approaches to ecosystem management and avoid further sidetracks and traps that distract us from real sustainable development.

Pierre L. Ibisch

Centre for Econics and Ecosystem Management, Faculty of Forest and Environment, Eberswalde University for Sustainable Development, Germany; E-Mail: pibisch@hnee.de 